\title{
O CONCEITO DE AGRICULTURA FAMILIAR: RETROCESSOS DO PRESENTE
}

THE CONCEPT OF FAMILY AGRICULTURE: RETREATS FROM THE PRESENT

EL CONCEPTO DE AGRICULTURA FAMILIAR: RETIROS DEL PRESENTE

\author{
Juliano Luiz Fossá ${ }^{1}$ \\ https://orcid.org/0000-0002-9658-4850 \\ Arlene Anélia Renk ${ }^{2}$ \\ https://orcid.org/0000-0002-3524-0739
}

Submissão: 30/11/2020/ Aceito: 09/03/2021 / Publicado: 31/03/2021.

\begin{abstract}
Resumo
Este artigo tem por objetivo demonstrar os retrocessos por parte do Governo Federal quanto ao entendimento do conceito de agricultura familiar a partir de meados do ano de 2016. O conceito de agricultura familiar, que parecia cristalizado desde o início da década de 1990, vê-se em torno de um novo entendimento que retrocede à ideia de pequeno produtor, pequena produção, superada há três décadas pela sociedade brasileira. A realização deste estudo apoiou-se na abordagem qualitativa, caracterizando-se como um ensaio teórico. Por meio de uma pesquisa bibliográfica foi analisada a literatura a respeito, bem como as medidas legais e ações políticas do Executivo Federal em relação à agricultura familiar no País. A reestruturação do Governo Federal a partir de maio de 2016 resultou na extinção do MDA. Esta medida, por sí só, representa que a agricultura brasileira a partir de então será tratada da mesma forma pelo Governo Federal, neste caso sob a tutela do MAPA. Outra medida é a criação do termo Unidade Familiar de Produção Agrária (UFPA) por meio do Decreto Presidencial 9.064/2017, que reduz a agricultura familiar somente à ideia de produção agropecuária. Trata-se de uma forma simplista de delinear toda diversidade presente no conceito de agricultura familiar, pois para além de um território produtivo, o rural se coloca como um espaço de vida. É possível concluir, que há uma série de medidas e ações do Governo Federal a partir de maio de 2016 destinadas a um "novo" entendimento do conceito de agricultura familiar. Tal percepção retrocede no tempo e simplifica um conceito complexo e amplo construído há muitas mãos durante décadas. O conceito de agricultura familiar é marcado por continuidades e rupturas, contudo uma ampla movimentação em torno desse debate se faz necessário para garantia, especialmente no que tange a políticas públicas diferenciadas.
\end{abstract}

Palavras-chave: Agricultura Familiar. Conceito. Governo Federal.

\begin{abstract}
This article aims to demonstrate the setbacks on the part of the Federal Government in understanding the concept of family farming from the middle of 2016. The concept of family

${ }^{1}$ Doutorando em Administração na Universidade Federal de Santa Catarina (UFSC). Analista Pleno na Universidade Comunitária da Região de Chapecó (UNOCHAPECÓ). E-mail: j.fossa@ unochapeco.edu.br

${ }^{2}$ Doutora em Antropologiapela Universidade Federal do Rio de Janeiro (UFRJ). Docente e Pesquisadora na Universidade Comunitária da Região de Chapecó (UNOCHAPECÓ). E-mail: arlene@ unochapeco.edu.br
\end{abstract}

DOI: http://dx.doi.org/10.22295/grifos.v30i54.5919 | Edição Vol. 30, Núm. 54, 2021. 
farming that seemed crystallized since the early 1990s is around a new understanding that goes back to the idea of small producer, small production surpassed three decades ago by Brazilian society. The realization of this study was supported by the qualitative approach, characterized as a theoretical essay. Through a bibliographic search, the literature was analyzed, as well as the legal measures and political actions of the Federal Executive in relation to family farming in the country. The restructuring of the Federal Government as of May 2016 resulted in the extinction of the MDA. This measure alone, represents that Brazilian agriculture will from then on be treated in the same way by the Federal Government, in this case under the tutelage of MAPA. Another measure is the creation of the term Family Unit for Agricultural Production (UFPA) through Presidential Decree 9,064 / 2017, which reduces family farming to the idea of agricultural production only. It is a simplistic way of portraying all the diversity present in the concept of family farming, because in addition to a productive territory, the rural is placed as a living space. It is possible to conclude that there are a series of measures and actions by the Federal Government as of May 2016 aimed at a "new" understanding of the concept of family farming. Such an understanding goes back in time and simplifies a complex and broad concept built for many hands over decades. The concept of family farming is marked by continuities and ruptures, however a wide movement around this debate is necessary for guarantee, especially with regard to different public policies.

Keywords: Family farming; Concept; Federal Government.

\section{Resumen}

Este artículo tiene como objetivo demostrar losretrocesos por parte del Gobierno Federal enlacomprensión del concepto de agricultura familiar desde mediados del año 2016. El concepto de agricultura familiar que parecía cristalizado desde principios de la década de 1990 está en torno a un nuevo entendimiento que se remonta alaidea de pequeñoproductor, pequeñaproducción superada hacetres décadas por lasociedadbrasileña. La realización de este estudio se basóenel enfoque cualitativo, caracterizado como unensayo teórico. Mediante una búsqueda bibliográfica, se analizóla literatura, así como las medidas legales y acciones políticas del Ejecutivo Federal enrelación a la agricultura familiar enel País. La reestructuración del Gobierno Federal a mayo de 2016 resultóenlaextinción de la MDA. Esta medida por sí sola, representa que la agricultura brasileña será a partir de entonces tratada de lamismamanera por elGobierno Federal, en este caso bajo la tutela del MAPA. Otra medida es lacreación del término Unidad Familiar de Producción Agraria (UFPA) mediante Decreto Presidencial 9.064 / 2017, que reducela agricultura familiar a laidea de producción agrícola únicamente. Es una forma simplista de retratar toda ladiversidad presente enel concepto de agricultura familiar, porque además de unterritorioproductivo, lo rural se coloca como espacio vital. Es posible concluir que existen una serie de medidas y acciones por parte del Gobierno Federal a mayo de 2016 dirigidas a una "nueva" comprensión del concepto de agricultura familiar. Tal comprensión se remonta eneltiempo y simplifica un concepto amplio y complejoconstruido durante décadas. El concepto de agricultura familiar está marcado por continuidades y rupturas, sin embargo es necesarioun amplio movimientoen torno a este debate para garantizarlo, especialmente enlo que respecta a las diferentes políticas públicas.

Palabras chave:Agricultura familiar. Concepto. Gobierno federal. 


\section{INTRODUÇÃO}

Este artigo é, antes de qualquer definição, o resultado de um esforço teórico em resgatar as definições conceituais daquilo que, desde o início dos anos de 1990, compreendíamos enquanto agricultura familiar no País. Dito isto, chamamos a atenção para a importância desse debate na atualidade, pois, desde meados de 2016, ocorreu uma ruptura quanto ao entendimento do Governo Federal às diferenciações existentes no interior da agricultura familiar brasileira. Para tanto, o objetivo deste trabalho é demonstrar os retrocessos impostos pelo Governo Federal quanto ao entendimento conceitual e valorização da agricultura familiar a partir de maio do ano de 2016.

Há muitas décadas, inúmeros pesquisadores se dedicaram para demonstrar à sociedade brasileira a importância da agricultura familiar no processo de desenvolvimento do País. A virada conceitual sobre esta questão ocorre a partir das publicações de Veiga (1991), Abramovay (1992) e Lamarche (1993) que foram capazes de apresentar ao meio acadêmico brasileiro o papel concedido à agricultura familiar por países de capitalismo avançado. Contudo, outros dois fatores contribuíram, igualmente, para que o Estado brasileiro reconhecesse o segmento familiar rural como um setor estratégico ao desenvolvimento rural. $\mathrm{O}$ primeiro diz respeito a um entendimento dos movimentos sociais do campo, especialmente aqueles ligados à Confederação Nacional dos Trabalhadores na Agricultura (CONTAG) que, ao longo das décadas anteriores foram se aproximando e no início da década de 1990, tinham em comum um entendimento daquilo que seria a agricultura familiar brasileira. O segundo fator é a realização de um estudo entre FAO/INCRA que, em linhas gerais, definiu as principais diretrizes da agricultura familiar no País.

Esse clima favorável desencadeou, em 1996, no governo Fernando Henrique Cardoso, o Programa Nacional de Fortalecimento da Agricultura Familiar (PRONAF) e a partir deste, no decorrer das três décadas seguintes, uma série de políticas públicas de fortalecimento e apoio destinadas exclusivamente ou não ao segmento da agricultura familiar brasileira. Pensar as políticas públicas leva a observar o grande mapa do organograma do Estado brasileiro e verificar a inserção da agricultura familiar. Tomemos como ponto de referência a breve trajetória do Ministério do Desenvolvimento Agrário (MDA), este Ministério deve ser abordado relacionalmente ao Ministério da Agricultura, Pecuária e Abastecimento (MAPA), que trata do agronegócio, dado à sua longevidade e anchas 
atribuições. Com o impedimento da então presidente Dilma Rousseff, Partido dos Trabalhadores (PT), e a consequente posse ao cargo do senhor Michel Temer, Movimento Democrático Brasileiro (MDB) em de 2016, ocorre uma ruptura quanto à trajetória de ações públicas em benefício ao segmento da agricultura familiar.

A partir de então, várias políticas públicas foram extintas e/ou tiveram significativo enxugamento dos recursos, como por exemplo, Programa de Aquisição de Alimentos (PAA) e o Programa Nacional de Desenvolvimento Sustentável dos Territórios (PRONAT). Além disso, ocorre desmonte institucional das esferas federais responsáveis por operacionalizar e gerenciar as políticas públicas de apoio ao segmento. Não obstante, ocorre a publicação de vários ordenamentos legais que alteram esse entendimento e a agricultura nacional passa a ser vista de uma forma mais homogênea. No governo de Jair Bolsonaro, Partido Social Liberal (PSL) ${ }^{3}$, esse entendimento permanece, pois, toda a estrutura da então Secretaria Especial da Agricultura Familiar (SEAF) passa a ser subordinada ao Ministério da Agricultura, Pecuária e Abastecimento (MAPA). Além disso, documentos oficiais do governo Bolsonaro assumem uma única "porta" para as demandas da agricultura brasileira.

Em termos metodológicos, este artigo adota uma abordagem qualitativa, caracterizando-se como um ensaio teórico. Além da revisão bibliográfica, a partir dos principais autores que definem o conceito de agricultura familiar no Brasil, buscou-se realizar uma análise das principais alterações legais perpetradas contra a agricultura familiar desde maio de 2016. Em termos de organização e estrutura, o trabalho conta com esta introdução, em seguida é esboçada a revisão teórica, bem como, apresentadas as ações do Governo Federal em relação à agricultura familiar. Por fim, são tecidas as considerações finais e relacionadas as referências bibliográficas indicadas ao longo do texto.

\section{A NOÇÃO CONCEITUAL: UM DEBATE AINDA NECESSÁRIO}

A noção de agricultura familiar para o conjunto da sociedade, enquanto segmento de fundamental importância ao desenvolvimento do País, parecia estar colocada e relativamente consolidada. Em editorial da Revista de Economia e Sociologia Rural alusivo à edição especial comemorativa ao Ano Internacional da Agricultura Familiar, Niederle, Fialho e

\footnotetext{
${ }^{3}$ Atualmente sem partido político.
} 
Conterato (2014, p. 12) reconhecem que as “[...] compreensões e reflexões sobre as dinâmicas econômicas, sociais, culturais e ambientais na agricultura familiar estão amplamente balizadas pelos debates que se produziram ao longo de diferentes momentos das ciências sociais brasileiras."

A noção que parecia cristalizada, mais propensa a passos progressivos de entendimento de grupos específicos no interior da agricultura familiar, transfere-se para um ambiente de ruptura a partir do impedimento da presidente Dilma Rousseff e posse, do então vice-presidente Michel Temer, no ano de 2016. A ruptura a qual nos referimos está associada ao desmonte das estruturas institucionais do Governo Federal, inclusive, o Ministério do Desenvolvimento Agrário (MDA), aos cortes orçamentários significativos e a descontinuidade de várias políticas públicas. As medidas tomadas pelo Governo Federal, a partir de maio de 2016, são consequências de uma mudança de entendimento sobre a agricultura nacional, em que a agricultura familiar perde espaço e novamente se encontra alijada da centralidade de atenções específicas do Estado Brasileiro.

Com esses aspectos introdutórios chamamos a atenção para a necessidade de se pautar novamente a noção conceitual de agricultura familiar no contexto de estudos e pesquisas que envolvam a temática. É prudente retomar as demarcações daquilo que significa a agricultura familiar no País em contraposição aos ataques de setores conservadores da sociedade brasileira, os quais são representadas pela Frente Parlamentar da Agricultura (FPA), ou simplesmente por seu nome mais popular "Bancada Ruralista”. Para além da contraposição, é necessário garantir que conquistas históricas, alcançadas com muita articulação, mobilização social e diálogo não sejam retiradas completamente do contexto brasileiro sob os interesses das minorias elitizadas que constituem o rural brasileiro.

Nesta perspectiva, apresentaremos à luz de autores reconhecidos no Brasil, que em seus estudos e pesquisas trabalharam a realidade do segmento no País, objetivando retomar os conceitos basilares que sustentam a agricultura familiar enquanto uma categoria analítica nas dimensões econômica, social, ambiental e política. É necessário ressaltar que a agricultura familiar nacional está inserida na complexidade do rural e os fatos históricos da sociedade brasileira marcaram fundamentalmente a noção conceitual no País.

No Brasil, a partir da segunda metade do século XX, as nomenclaturas designantes à agricultura familiar se constituíam de várias formas, como produtores familiares, produtores de baixa renda, agricultores de subsistência, pequenos produtores ou outras atribuições 
regionais. Seyferth (2011) tece elogios à iniciativa do Ministério do Desenvolvimento Agrário (2009) por organizar e publicar em cinco volumes a produção acerca da diversidade do campesinato brasileiro, nas suas experiências, manifestações culturais e resistências. Pesquisadores dos diversos quadrantes do País contribuíram para a realização do trabalho. A informação que ora trazemos no sentido de ampliar os horizontes para além da nomenclatura tratada habitualmente na literatura. Não se trata de catálogo ou decálogo, ao contrário, de um leque de nominações que ocorrem pelo País.

De todo modo, outros grupos também se inserem no conjunto, dada essa perspectiva histórica, como os indígenas, pescadores, aquicultores, etc.

As diretrizes do Estatuto da Terra, Lei Federal n. 4.504/1964, bem como os ordenamentos estabelecidos pelo Sistema Nacional de Crédito Rural (SNCR), Lei Federal n. 4.829/1965, reforçam o entendimento de que a agricultura familiar naquele período representava a ideia da pequena produção. Esses aspectos, coadunados com os processos agregados da modernização, predomina no Brasil no decorrer das décadas de 1970 e 1980 a compreensão do termo da pequena propriedade, da pequena produção e do pequeno agricultor. Estes termos foram claramente submetidos à dependência ideológica das unidades familiares de agricultura frente às grandes propriedades rurais ${ }^{4}$.

A multiplicidade das formas conceituais quanto à agricultura familiar no País constitui-se em um jogo de relações, de forças e questões ideológicas que estiveram em gestação a partir dos anos de 1960 (PORTO; SIQUEIRA, 1994).

\begin{abstract}
As reflexões contidas nos estudos realizados sobre a temática do campo, nas últimas décadas, indicam um esforço de compreensão das transformações ocorridas na sociedade e de construção da explicação dessas transformações. Mas envolvendo, ao mesmo tempo, um jogo de relações de forças entre correntes de pensamento, em um movimento marcado, em última estância, pela busca do estabelecimento e da manutenção de espaços teóricos hegemônicos. (PORTO; SIQUEIRA, 1994, p. 26).
\end{abstract}

Segundo Schneider (2003), o debate sobre os grupos que hoje constituem a agricultura familiar nas Ciências Sociais brasileiras não é recente e demarca uma longa tradição de estudos e pesquisas, outrora classificados de outras denominações. Na mesma direção, Niederle, Fialho e Conterato (2014) reconhecem a existência de um amplo conjunto

4 Entre os vários objetivos das questões ideológicas postas está a deslegitimação da necessidade da reforma agrária no País. Ressalta-se que o debate sobre a reforma agrária ainda está colocado perante a sociedade brasileira. Detalhes em Mattei (2014a). 
de autores brasileiros, os quais, principalmente entre 1940 e 1980, produziram reflexões importantes no debate sobre a agricultura familiar brasileira. Para os autores, esse movimento da ciência brasileira foi fundamental no sentido de institucionalizar os estudos construídos em relação à temática nas últimas três décadas no Brasil (NIEDERLE; FIALHO; CONTERATO, 2014).

O conceito de agricultura familiar não é único, pelo contrário, não se constitui de forma estática, modifica-se, transformando-se com o passar dos anos sob às dinâmicas do ambiente no qual está inserido. Para Seyferth (2011, p. 397), as “definições são ferramentas do pensamento e não verdades que duram para sempre". Posto isso, recorremos à uma perspectiva histórica para compreender uma noção do conceito da agricultura familiar enquanto uma categoria analítica no País.

No entendimento de Schneider (2009), a compreensão da noção de agricultura familiar exige análises sociológicas de múltiplas dimensões sobre a ampla diversidade de suas formas sociais. Na mesma direção, Moreira (2013) afirma que as definições das expressões da agricultura familiar se constituem em elementos criteriosos de identificação dos sujeitos analisados e de seus territórios, seu contexto social, econômico e cultural. Segundo estudo publicado em 2016 pelo Instituto Interamericano de Cooperação para a Agricultura Familiar (IICA), a amplitude da percepção é uma condição necessária para compreensão de que a agricultura familiar abrange distintos segmentos que se diferenciam tanto em termos de organização socioeconômica como nas características advindas da dispersão espacial.

O estudo da diversidade da agricultura familiar requer uma análise multidimensional sobre as formas de organização do trabalho e da produção no âmbito da unidade de produção familiar, entendidas como mecanismos de construção das estratégias de interação que os agricultores estabelecem com a natureza - a forma de fazer agricultura - e o ambiente social e econômico em que estas relações se estabelecem. Portanto, o entendimento da diversidade da agricultura familiar passa pela identificação das dinâmicas territoriais de desenvolvimento rural, das estratégias individuais e coletivas de reprodução social e das situações de diferenciação social que daí resultam. (CONTERATO, 2008, p. 86).

O marco inicial de considerações acerca da agricultura familiar é que este segmento se configura em um conceito amplo e genérico, pois contempla grande diversidade de grupos sociais e de formas de organização socioeconômica (WANDERLEY, 1999). Nos termos de Lamarche (1993-1997), a agricultura familiar enquanto segmento não é constituído a partir 
da diversificada, mas porque no seu próprio interior está inserida toda a diversidade. Nessa esteira assumimos a significativa heterogeneidade dos grupos, sujeitos e das formas de organização social que constituem a agricultura familiar.

Em linhas gerais, para um significativo conjunto de autores está consolidado que a agricultura familiar significa dizer que a família detém uma relação de apropriação com o estabelecimento rural, dos meios de produção e também se responsabiliza pelo trabalho produtivo, ou pelo menos a maior parte, realizado no âmbito da propriedade (VEIGA, 1991; ABRAMOVAY, 1992; LAMARCHE 1993-1997; WANDERLEY, 1999; BLUM, 1999). Contudo, há particularidades na contribuição teórica de cada autor, aspecto esse que ressalta a condição de que a noção da agricultura familiar, na realidade brasileira, está configurada em uma perspectiva Lato Sensu.

Wanderley (2003) compreende que a agricultura familiar pode ser entendida como aquela em que a família é a proprietária dos meios de produção e ao mesmo tempo assume o trabalho na propriedade rural, apresentando, assim, uma significativa diversidade nas formas sociais de organização socioprodutiva.

Na visão de Abramovay (2003), a agricultura familiar apresenta multiplicidades de perspectivas e de atores sociais que vão muito além das questões produtivas, abrangendo laços sociais de ligação entre indivíduos e suas organizações. Em complemento, o Fundo Internacional de Desenvolvimento Agrícola (FIDA) (2014, p. 8), no âmbito da América Latina, classifica a agricultura familiar como aquela que: "Se refiere al ejercicio de uma actividad económica, la agricultura, por parte de um grupo social unido por lazos de parentesco e de sangre, la família, que trabaja y genera produtos, bienes e servicios.”

Em torno disso, Abramovay (1992) aponta que para uma compreensão da noção conceitual da agricultura familiar é condicionado ao investigador uma busca profunda nos aspectos sociais, ambientais, econômicos e culturais. Em outras palavras, assumimos que as definições no interior da base da agricultura familiar são diversas e condicionadas às suas esferas sociais, espaciais e econômicas. Veiga (1991, p. 1991), por sua vez, afirma que o importante nesta discussão é: "Tentar entender o sentido geral do movimento histórico que fez com que a agricultura familiar tenha predominado de forma nítida em todos os Países capitalistas desenvolvidos neste século."

A contribuição de Lamarche (1993-1997, p. 15) remete à exploração familiar na agricultura como uma noção ambígua, pois o significado de agricultura familiar corresponde 
ao mesmo tempo a uma “[...] unidade de produção agrícola onde a propriedade e o trabalho estão intimamente ligados à família." O autor apresenta a agricultura familiar em um grande eixo onde se situam as mais diversas formas de exploração familiares. $\mathrm{O}$ eixo tem de um lado aquilo que o autor considera de modelo original e do outro o modelo ideal. No modelo original seriam as formas mais tradicionais de agricultura, enquanto o ideal se configuraria mais próximo das características empresariais e se organizaria em uma etapa na qual os agricultores familiares, dadas as suas condições, almejassem alcançar (LAMARCHE, 19931997).

Não se trata especificamente de um ponto de partida e um ponto de chegada, como o próprio Hugues Lamarche nos alerta, mas de caminhos e estratégias tomadas pelos agricultores em relação ao futuro deles, da família e da propriedade enquanto produção e espaço de vida. É nesta trajetória histórica que se estabelece um novo sujeito social nas formas familiares de exploração da agricultura, ou seja, o agricultor familiar moderno. Segundo Lamarche (1993-1997), esse novo sujeito social não representa as formas camponesas, tampouco o modelo empresarial.

Do ponto de vista do estabelecimento rural, a agricultura familiar moderna caracteriza-se principalmente por ser menos intensiva nos processos produtivos, menos dependente financeiramente e com certa retração em relação aos mercados. Ainda na visão de Lamarche (1993-1997, p. 314): “O estabelecimento familiar moderno funciona sensivelmente como estabelecimento de tipo camponês, com mais técnica e mais necessidades." Para Veiga (1991), as diferenças fundamentais entre a agricultura familiar e modelos tradicionais de agricultura constituem-se basicamente em duas: a primeira ligada ao grau de integração aos mercados; e a segunda ligada a própria limitação desses mercados.

No que diz respeito à importância da família na concepção de agricultura familiar moderna, Lamarche (1993-1997) aponta para manutenção da ideia do desenvolvimento do patrimônio familiar, contudo, as atitudes do novo sujeito se aproximam da perspectiva empresarial. Em relação à utilização da mão de obra, o agricultor familiar moderno também valoriza o trabalho familiar, porém, permite-se a utilização da contratação de mão de obra externa à propriedade. Assume-se novamente certa aproximação com o modelo empresarial, pois, a mão de obra da família pode passar a não ser essencial para o funcionamento da propriedade familiar. Na agricultura familiar contemporânea observa-se a escolarização de seus integrantes, como fruto do processo de escolarização obrigatória, ao contrário do que 
ocorria em gerações anteriores. A clivagem de gênero é mais atenuada, contando com maior participação das mulheres na esfera da vida da propriedade.

As características essenciais da agricultura familiar não rompem completamente com as heranças do passado, assim como não se molda exclusivamente ao espaço, ambiente e às condições atuais do presente. Em relação às unidades familiares, Wanderley $(1999 ; 2003)$ e Ploeg (2016) apontam que há certamente processos de continuidades, bem como processos de descontinuidades quanto à forma de organização e reprodução social. Os padrões hereditários na atualidade são mais equalizados, obedecendo ao cálculo e orientação familiar.

Os conhecimentos, a cultura, a forma de agir, tanto social como economicamente, são aspectos transmitidos de geração para geração e que se colocam em possibilidades de processos de continuidades. Quanto à forma de organizar a produção, as técnicas e métodos utilizados, bem como a forma de interagir e se relacionar com os mercados é, sem dúvidas, o resultado de processos descontínuos que inserem o agricultor familiar em uma nova condição, uma nova forma de interação com a sociedade (WANDERLEY, 2015). Em apoio a esta afirmação, Conterato (2008, p. 77) admite que: “A diversidade da agricultura familiar é tanto o resultado de negociação interna para alocação de recursos produtivos como da influência dos agentes externos." Há práticas camponesas que foram se esgarçando e se perdendo no tempo, como as do mutirão, que pode ocorrer eventualmente, e a da distribuição da carne do porco abatido na propriedade, quando cabia a cada vizinho determinado corte. No entanto, outras práticas são cultivadas, inventas tradições, como alimentares dos "tempos antigos", a língua dialetal falada pelos avós que, de estigma vira emblema, o cultivo de plantas medicinais e o impulso a agroecologia. Nesse último caso, advogam-se o papel de guardiã da natureza, em oposição ao agronegócio e seus "venenos".

A relação com o Estado também é abordada por Lamarche (1993-1997) ao caracterizar a agricultura familiar moderna. Segundo o autor, o novo sujeito social, com maior grau de especialização e profissionalização, se constrói com certa dependência perante o Estado, especialmente no que se trata à questão agrícola de estímulos à produção. Nesses termos, o agricultor familiar moderno é resultado de seu posicionamento intermediário entre o modelo camponês e o empresarial, um sujeito mais preparado ao enfrentamento das situações de ambiente devido a estar aberto tanto às tradições como à modernidade (LAMARCHE, 1993-1997). 
O estabelecimento familiar moderno é, portanto, uma unidade de produção que procura conservar nela mesma todas as potencialidades necessárias, tanto de ordem técnico-econômica quanto social e cultural, para modificar, conforme as circunstâncias, seus comportamentos e operar estratégias de adaptação. (LAMARCHE, 1993-1997, p. 326).

Nesta perspectiva de análise, Veiga (1991) aponta que a agricultura familiar nos países capitalistas contou com apoio do Estado em relação a todos os meios necessários para seu desenvolvimento. Abramovay (1992) enfatiza que a agricultura familiar do final do século XX, nos países de capitalismo avançado, é reflexo diretamente da ação estatal. Para o autor, a agricultura familiar moderna rompe totalmente com suas características camponesas ao se constituir com plenas possibilidades de desenvolvimento em economias capitalistas. Em síntese, a agricultura familiar na concepção de Abramovay (1992) é uma criação do Estado.

\begin{abstract}
O que mudou na agricultura dos Países capitalistas centrais não foi apenas sua base técnica, ou sua integração a conjuntos econômicos que extrapolam o setor: a característica central da agricultura moderna está exatamente na capacidade que ela oferece ao Estado de exercer um controle rigoroso sobre seu próprio processo de desenvolvimento. (ABRAMOVAY, 1992, p. 265-266).
\end{abstract}

A obra de Abramovay (1992) clarificou para o conjunto da sociedade brasileira que, nos países de capitalismo avançado, as formas familiares de agricultura possuíam um papel decisivo na oferta agropecuária, desmistificou a ideia da "pequena produção" e mostrou-a enquanto categoria central para a promoção do desenvolvimento nesses países. Somam-se à nova inflexão sobre o papel da agricultura familiar nos processos de desenvolvimento econômico as contribuições de Veiga (1991) e Lamarche (1993-1997).

$\mathrm{Na}$ agricultura familiar brasileira, os tempos dourados foram aqueles em torno da conquista da identidade de agricultor familiar, acumulados nas lutas anteriores, como os direitos previdenciários, a consolidação de movimentos sociais como o Movimento dos Sem Terra, Movimento das Mulheres Agricultoras e depois Movimento das Mulheres Camponesas e as lutas sindicais (CORADINI, 1989).

A “virada conceitual” no início dos anos de 1990, a qual mencionamos na introdução, deve ser considerada como resultado das discussões ocorridas no meio acadêmico brasileiro desde meados do século XX. Para Schneider (2003), esses estudos publicados no início dos anos de 1990 colaboraram para um maior entendimento quanto à definição da agricultura familiar no Brasil. Segundo o autor: "O maior mérito desses estudos talvez tenha sido o fato 
de terem revelado que a agricultura familiar é uma forma social reconhecida e legitimada na maioria dos Países desenvolvidos [...]” (SCHNEIDER, 2003, p. 29).

Sobre o novo significado da agricultura familiar no Brasil, Schneider e Cassol (2017, p. 85) apontam que:

\begin{abstract}
O reconhecimento da agricultura familiar se refere a um movimento ou esforço cognitivo e às vezes político-retórico para requalificar e renomear a forma como os camponeses e pequenos produtores eram até então definidos. Mas, por outro lado, trata-se também de atribuir um novo sentido analítico e político, pois a agricultura familiar passa a ser entendida como uma categoria social diversa e heterogênea pelos estudiosos e cientistas e vista pelos gestores governamentais e os atores e organizações sociais pelo seu papel estratégico no processo de desenvolvimento social e econômico.
\end{abstract}

As contribuições conceituais do meio intelectual nesse período foram, e ainda são, fundamentais para compreensão da noção em torno da categoria de agricultura familiar, especialmente em relação à realidade brasileira. Isto porque, até a década de 1980, existiam as mais variadas formas de nomenclatura, as quais puderam a partir dos anos de 1990 serem aglutinadas em um único conceito, amplo e genérico, conforme já destacamos anteriormente. Além das contribuições do conjunto de pesquisadores, outros dois aspectos contribuíram fundamentalmente para o avanço da compreensão da categoria da agricultura familiar.

O segundo aspecto é no sentido de que a noção da agricultura familiar, do início dos anos de 1990, foi adotada pela maior parte dos movimentos sociais do campo brasileiro, tal como a Confederação Nacional dos Trabalhadores na Agricultura (CONTAG). A necessidade de construção de pautas e demandas unificadas colaborou expressivamente para tais caracterizações e definições conceituais em torno da agricultura familiar.

O terceiro aspecto pode ser considerado a realização de um estudo em parceria entre FAO/INCRA no ano de 1994 sob a demanda do Estado brasileiro que resultou no estabelecimento das principais diretrizes à agricultura familiar no País. Ao mencionar as particularidades da agricultura familiar frente à agricultura patronal naquele período, o relatório apontou:

\footnotetext{
A agricultura patronal, com suas levas de boias-frias e alguns poucos trabalhadores residentes vigiados por fiscais e dirigidos por gerentes, engendra forte concentração de renda e exclusão social, enquanto a agricultura familiar, ao contrário, apresenta um perfil essencialmente distributivo, além de ser incomparavelmente melhor em termos socioculturais. Sob o prisma da sustentabilidade (estabilidade, resiliência e equidade), são imensas as vantagens apresentadas pela organização familiar na produção agropecuária, devido à sua
} 
ênfase na diversificação e à maior maleabilidade de seu processo decisório. (FAO; INCRA, 1994, p. 5).

Brose (1999) sintetiza as vantagens da agricultura familiar mencionadas no estudo da FAO/INCRA em: i) estabilidade e capacidade de adaptação; ii) diversidade produtiva; iii) maleabilidade de seu processo decisório. O referido documento ainda caracterizou a agricultura familiar brasileira em seis aspectos principais: i) trabalho e gestão intimamente relacionados; ii) direção do processo produtivo assegurada diretamente pelos proprietários; iii) ênfase na diversificação; iv) ênfase na durabilidade dos recursos e na qualidade de vida; v) trabalho assalariado complementar; vi) decisões imediatas, adequadas ao alto grau de imprevisibilidade do processo produtivo (FAO; INCRA, 1994).

Apesar de ser complexa uma definição única sobre a agricultura familiar, entre as possibilidades para uma classificação geral constitui-se a partir das formas e da organização social do processo produtivo que, essencialmente, caracterizam-se pelos seguintes aspectos: i) utilização de mão de obra essencialmente familiar na propriedade; ii) parte dos rendimentos do grupo familiar advindos das atividades rurais da propriedade; iii) produção diversificada, especialmente para o autoconsumo; iv) estabelecimentos rurais com tamanho máximo de até quatro módulos fiscais.

Em relação a categorias no interior da agricultura familiar, a FAO e INCRA (1994) estratificou o segmento familiar brasileiro a partir de três segmentos, ou seja, unidades familiares consolidadas, unidades familiares em transição e unidades familiares de subsistência. As unidades familiares consolidadas são aquelas que dispõem dos mecanismos de comercialização agrícola de forma regular, o que garante a reprodução da força de trabalho. As unidades familiares em transição constituem-se pela parcialidade e fragilidade de integração aos mercados, baixo nível de rendimentos e sujeitos aos desequilíbrios que podem levar ao abandono da atividade. Já as unidades familiares de subsistência caracterizam-se pela concentração no autoconsumo e na venda da mão de obra sazonal (BROSE, 1999).

Uma delimitação genérica e/ou uma classificação geral à agricultura familiar orientanos quanto ao propósito do Estado em oferecer programas e políticas específicas para determinada categoria social (GUANZIROLI et al., 2001). Desse modo, a noção e/ou a definição no plano institucional são fundamentais no âmbito da esfera do Governo Federal. 
No âmbito do Estado brasileiro, a partir da criação do Pronaf em 1996, é a Declaração de Aptidão ao Pronaf (DAP) que assegura ao agricultor a condição de pertencer ao segmento da agricultura familiar. A referida declaração constitui-se como requisito para acesso aos programas específicos de apoio à categoria da agricultura familiar. Em termos de uma legislação específica, somente em 2006, por meio da Lei Federal n. 11.326, são estabelecidas as diretrizes à agricultura familiar no País.

Os critérios do Art. $3^{\circ}$ da Lei n. 11.326/2006 determinam as seguintes condições para enquadramento de agricultores no segmento familiar: i) não detenha, a qualquer título, área maior do que quatro módulos fiscais; ii) utilize predominantemente mão de obra da própria família nas atividades econômicas do seu estabelecimento ou empreendimento; iii) tenha pelo menos $50 \%$ da renda familiar originada de atividades econômicas do seu estabelecimento ou empreendimento, na forma definida pelo Poder Executivo ${ }^{5}$; iv) dirija seu estabelecimento ou empreendimento com sua família (BRASIL, 2006). Para além dos agricultores historicamente classificados como tal, a Lei Federal n. 11.326/2006 considera agricultores familiares os seguintes grupos, conforme disposto no Quadro 1.

Quadro 1 - Grupos considerados Agricultores Familiares segundo a Lei Federal n. 11.326/2006.

\begin{tabular}{|l|l|}
\hline Grupo I & $\begin{array}{l}\text { Silvicultores que cultivem florestas nativas ou exóticas e que promovam o manejo } \\
\text { sustentável daqueles ambientes; }\end{array}$ \\
\hline Grupo II & $\begin{array}{l}\text { Aquicultores que explorem reservatórios hídricos com superfície total de até dois hectares } \\
\text { ou ocupem até quinhentos metros cúbicos de água, quando a exploração se efetivar em } \\
\text { tanques-rede; }\end{array}$ \\
\hline Grupo III & $\begin{array}{l}\text { Extrativistas que exerçam essa atividade artesanalmente no meio rural, excluídos os } \\
\text { garimpeiros e faiscadores; }\end{array}$ \\
\hline Grupo IV & Pescadores que exerçam a atividade pesqueira artesanalmente; \\
\hline Grupo V & Povos indígenas que atendam aos requisitos previstos no Art. $3^{\circ}$ da referida lei ${ }^{6} ;$ \\
\hline Grupo VI & $\begin{array}{l}\text { Povos integrantes de comunidades remanescentes de quilombos rurais e demais povos e } \\
\text { comunidades tradicionais que atendam aos requisitos previstos no Art. } 3^{\circ} \text { da referida lei } ;\end{array}$ \\
\hline Grupo VII & $\begin{array}{l}\text { Silvicultores que cultivem florestas nativas ou exóticas e que promovam o manejo } \\
\text { sustentável daqueles ambientes; }\end{array}$ \\
\hline Grupo VIII & $\begin{array}{l}\text { Aquicultores que explorem reservatórios hídricos com superfície total de até dois hectares } \\
\text { ou ocupem até quinhentos metros cúbicos de água, quando a exploração se efetivar em } \\
\text { tanques-rede. }\end{array}$ \\
\hline
\end{tabular}

Fonte: Lei n. 11.326/2006, elaboração do autor.

Ainda na perspectiva institucional, a partir da classificação de agricultura familiar, por meio da Lei Federal n. 11.326/2006, foi possível incluir na metodologia do Censo Agropecuário do mesmo ano, regras que permitiram a publicação de um conjunto de

\footnotetext{
5 Redação dada pela Lei n. 12.512, de 2011, e Decreto n. 9.064, de 2017.

Incluído pela Lei n. 12.512, de 2011.

7 Incluído pela Lei n. 12.512, de 2011.
}

DOI: http://dx.doi.org/10.22295/grifos.v30i54.5919 | Edição Vol. 30, Núm. 54, 2021. 
estatísticas sobre a agricultura familiar no País. Mais recentemente, em 2017, outra mudança no plano institucional marca a configuração do entendimento em relação à agricultura familiar, contudo, como será apresentado, esta alteração reflete uma ruptura com o que vinha sendo construído no País.

Referimo-nos à expedição do Decreto Presidencial n. 9.064, de 31 de maio de 2017, o qual dispõe sobre a Unidade Familiar de Produção Agrária, institui o Cadastro Nacional da Agricultura Familiar nos termos da Lei n. 11.326/2006. A primeira consideração está relacionada ao termo "Agrária" do termo Unidade Familiar de Produção Agrária (UFPA), pois ele representa uma forma simplista de retratar toda diversidade presente na agricultura familiar brasileira. Remete-nos ainda a um passado distante, que se pensava superado, no qual a agricultura nacional era sinônimo da produção agrícola. Além disso, nas ciências sociais, principalmente na economia e na sociologia, o termo "agrária" está relacionado à questão da posse da terra.

Uma segunda consideração do referido decreto diz respeito à alteração do texto de um dos incisos do Art. $3^{\circ}$ da Lei n. 11.326/2006, que trata dos requisitos para enquadramento no conceito de agricultura familiar no plano institucional. A exigência trata da questão dos rendimentos oriundos das atividades no âmbito da propriedade rural, especificamente estabelece um percentual mínimo para o enquadramento enquanto agricultura familiar. A partir de então, o parâmetro da UFPA se altera de: "tenha percentual mínimo da renda familiar originada de atividades econômicas do seu estabelecimento ou empreendimento"; para: "auferir, no mínimo, metade da renda familiar de atividades econômicas do seu estabelecimento ou empreendimento" (BRASIL, 2017, p. 1). Em síntese, esta alteração pode reduzir significativamente o contingente pertencente ao segmento rural familiar, pois, ao se considerar a noção de pluriatividade, um significativo número de estabelecimentos pode não se enquadrar mais nos termos da UFPA.

A terceira consideração ressalta a criação do Cadastro Nacional da Agricultura Familiar (CAF), o qual teve por finalidade a identificação e a qualificação da UFPA e do empreendimento familiar rural. Segundo o decreto, o CAF substituirá a DAP no que se refere ao documento de acesso às ações e às políticas públicas destinadas à UFPA e também aos empreendimentos familiares rurais. Contudo, mesmo após dois anos da publicação do Decreto Presidencial 9.064/2017, o CAF não foi efetivado e a DAP continua sendo o 
documento efetivo por parte dos agricultores familiares para aceso às políticas públicas de fortalecimento do segmento.

Estas definições conceituais e terminológicas em relação à agricultura familiar revestem-se de ampla complexidade. Um debate que continua aberto e no contexto atual sujeito a alterações que representem conquistas históricas do segmento. Ao conjunto da sociedade, aos estudiosos da temática e aos próprios agricultores familiares, faz-se necessário ampla discussão daquilo que é e do que representa a agricultura familiar brasileira. Nesses termos, é fundamental proceder o resgate dos condicionantes que legitimaram a importância da agricultura familiar no passado e, ao mesmo tempo, possa reconhecer os valores do segmento no desenvolvimento nacional perante o Estado brasileiro na atualidade.

A agricultura familiar não se desvincula da Reforma Agrária. O cômputo de Agricultores familiares estabelecidos, de modo consolidado, depende de algumas variáveis, como a da reforma agrária. Por muito tempo, no caso brasileiro, ela foi tabu, quando não motivo de repressão. Na década de 1980 foi criado o Ministério Extraordinário para Assuntos Fundiários (MEAF) transformado em Ministério da Reforma e do Desenvolvimento Agrário (MIRAD), depois recebeu a rubrica de Ministério da Política Fundiária e Agricultura Familiar, mais tarde em Ministério da Política Fundiária e do Desenvolvimento Agrário, até a criação do Ministério do Desenvolvimento Agrário (MDA). Nessas andanças foram se institucionalizando políticas públicas essenciais como o Programa Nacional de Educação na Reforma Agrária (PRONERA) e o Programa Nacional de Habitação Rural (PNHR).

No entanto, após 2016, o MDA é extinto e suas competências passam ao Ministério do Desenvolvimento Social (MDS), com o qual coabitou até a transferência à Secretaria Especial de Agricultura Familiar e do Desenvolvimento Agrário da Casa Civil da Presidência da República (SEAD), das competências do MDS para a Secretaria Especial de Agricultura Familiar e do Desenvolvimento Agrário da Casa Civil da Presidência da República (SEAD), criada em maio de 2016 (decreto $n^{\circ}$ 8.780), subordinado à Chefia da Casa Civil.

O Decreto $n^{\circ}$ 20.252/2020, criado no governo de Jair Bolsonaro, que reorganizou a estrutura do INCRA, solapou programas de Reforma Agrária e foi a pá de cal ao PRONERA, considerado uma política pública da reforma agrária voltada à educação no campo. A extinção da Coordenação da Educação do Campo, um Programa cambaleante, mostra mais uma vez a fragilização de políticas voltadas à agricultura familiar, num de seus segmentos mais vulnerabilizados. 
O Programa de Habitação Rural (PNHR), vinculado à Caixa Econômica Federal, que visava moradia digna aos moradores do campo, em 2020, com artifício orçamentário de prorrogação dos projetos e sob alegação de falta de recursos, houve expiração de prazo. Se a paisagem rural em parte mudou pela implementação do PNHR, o retrocesso instalado não deixa margem de novas mudanças.

\section{CONSIDERAÇÕES FINAIS}

Ao se propor esta temática de discussão, buscou-se sensibilizar a respeito de um fenômeno social emergente e, por sua vez, associado à ruptura de uma longa construção histórica em torno do conceito de agricultura familiar no País. Ao considerar esse fato, julgase necessário uma ampla frente de debates e articulações para que a agricultura familiar torne a ter espaço nas esferas institucionais e, principalmente, a compreensão por parte do Estado brasileiro em relação a necessidades de políticas públicas específicas de fortalecimento ao segmento. Isto porque, ao considerar a heterogeneidade e diversidade das formas de agricultura familiar brasileira não é aceitável que todas elas sejam tratadas pelo Estado brasileiro padronizadas homogeneamente.

Do mesmo modo, é necessário também que as condições para valorização do segmento sejam claras para todo o conjunto da sociedade, pois somente com engajamento será possível que as demandas e oportunidades específicas à agricultura familiar tenham novamente espaço e força política diante ao Governo Federal. Retomar as ações e políticas públicas não significa propriamente repetir as estratégias do passado mas, sim, a partir do entendimento conceitual do que é a agricultura familiar no País construir democraticamente novas estratégias de fomento ao desenvolvimento do setor.

Por fim, ressaltamos a importância de estudos que abordem esta problemática neste momento tão peculiar, tanto da compreensão teórica como da ambiência política do Estado brasileiro à agricultura familiar. Ao desconsiderar um segmento tão importante do ponto de vista social e econômico, o Estado brasileiro perde uma oportunidade de continuidade de estratégias e ações em prol do fortalecimento de toda a categoria da agricultura familiar. Os custos dessa visão homogênea sobre a agricultura brasileira são complexos e poderão ser mensurados futuramente. 
A diversidade da agricultura familiar do âmbito territorial brasileiro, reinsere a dimensão do jogo político, alijando considerável fração societária de uma organização estatal, em forma de ministério, autarquia e, fundamentalmente, no enxugamento das rubricas orçamentárias, de modo a privar as políticas públicas já consolidadas. Mesmo ante a “desresponsabilização" estatal, organizações, nascidas sem o apoio governamental, trabalham para apontar à sociedade o papel da agricultura familiar. Os olhares em direção à agricultura familiar não podem ignorar o jogo de alianças da política (de p minúsculo) que move o xadrez institucional. Não só a agricultura familiar, outros setores societários também sofrem os reveses de direitos conquistados.

\section{REFERÊNCIAS}

ABRAMOVAY, Ricardo. Paradigmas do capitalismo agrário em questão. São Paulo: Hucitec, 1992.

O futuro das regiões rurais. Porto Alegre: UFRGS, 2003.

BLUM, Rubens. Agricultura Familiar: estudo preliminar da definição, classificação e Problemática. In: TEDESCO, João Carlos (Org.). Agricultura familiar: realidades e perspectivas. Passo Fundo: Editora da UPF, 1999. p. 57-103.

BRASIL. Lei n. 4.504, de 30 de novembro de 1964.Dispõe sobre o Estatuto da Terra, e dá outras providências. Diário Oficial [da] República Federativa do Brasil, Brasília, DF, 30 nov. 1964.

. Lei n. 11.326, de 24 de julho de 2006. Estabelece as diretrizes para a formulação da Política Nacional da Agricultura Familiar e Empreendimentos Familiares Rurais. Diário Oficial [da] República Federativa do Brasil, Brasília, DF, 24 jul. 2006.

Lei n. 12.512, de 14 de outubro de 2011. Institui o Programa de Apoio à Conservação Ambiental e o Programa de Fomento às Atividades Produtivas Rurais. Diário Oficial [da] República Federativa do Brasil, Brasília, DF, 14 out. 2011.

Decreto n. 9.064, de 31 de maio de 2017. Dispõe sobre a Unidade Familiar de Produção Agrária, institui o Cadastro Nacional da Agricultura Familiar e regulamenta a Lei $\mathrm{n}^{\mathrm{o}}$ 11.326, de 24 de julho de 2006, que estabelece as diretrizes para a formulação da Política Nacional da Agricultura Familiar e empreendimentos familiares rurais. Diário Oficial [da] República Federativa do Brasil, Brasília, DF, 31 maio 2017.

BROSE, Markus. Agricultura familiar, desenvolvimento local e políticas públicas. Santa Cruz do Sul: EDUNISC, 1999. 
CONTERATO, Marcelo. Dinâmicas regionais do desenvolvimento rural e estilos de agricultura: uma análise a partir do Rio Grande do Sul. 2008. 288 f. Tese (Doutorado em Desenvolvimento Rural) - Universidade Federal do Rio Grande do Sul, Porto Alegre, 2008.

CORADINI, Odaci Luiz. Representações sociais e conflitos nas políticas de saúde e previdência social rural. Rio de Janeiro: Museu Nacional/UFRJ, 1989 (tese de doutorado em Antropologia Social).

FAO - Organização das Nações Unidas para a Alimentação e a Agricultura; INCRA Instituto Nacional de Colonização e Reforma Agrária do Brasil. Diretrizes de política agrária e desenvolvimento sustentável. Resumo do Relatório Final do Projeto UTF/BRA/036, segunda versão. Brasília: FAO/INCRA, 1994.

FIDA - Fundo Internacional de Desenvolvimento Agrícola. La agricultura familiar en América Latina: un nuevo análisis comparativo. Buenos Aires: FIDA, 2014.

GUANZIROLI, Carlos et al. Agricultura familiar e reforma agrária no século XXI. Rio de Janeiro: Garamond, 2001.

IICA - Instituto Interamericano de Cooperação para a Agricultura. La agricultura familiar en las Américas: principios y conceptos que guían la cooperación técnica del IICA. San José: IICA, 2016.

LAMARCHE, Hugues. A agricultura familiar: comparação internacional - uma realidade multiforme. Campinas: Fundação de Desenvolvimento da UNICAMP, 1993-1997. v. 1.

. Agricultura familiar: comparação internacional - do mito à realidade. Campinas: Ed. da Unicamp, 1993-1997. v. 2.

MOREIRA, Vilson Alves. Educação do campo e docência no contexto da agricultura familiar: o Programa Escola Ativa (PEA/MEC) no município de Salinas - MG. 2013. 211 f. Tese (Doutorado em Desenvolvimento Rural) - Universidade Federal do Rio Grande do Sul, Porto Alegre, 2013.

NIEDERLE, Paulo André; FIALHO, Marco Antônio Verardi; CONTERATO, Marcelo Antônio. A pesquisa sobre agricultura familiar no Brasil: aprendizagens, esquecimentos e novidades. Revista de Economia e Sociologia Rural, Piracicaba, v. 52, Supl. 1, p. S009S024, 2014.

ONU - Organização das Nações Unidas. Ano Internacional da Agricultura Familiar. 2014. Disponível em: <https://nacoesunidas.org/>. Acesso em: 20 mar. 2019.

PLOEG, Jan Douwe van der. Camponeses e a arte da agricultura: um manifesto Chayanoviano. São Paulo: Editora Unesp; Porto Alegre: Editora UFRGS, 2016.

PORTO, Maria Salete G.; SIQUEIRA, Deis E. A pequena produção no Brasil: entre os conceitos teóricos e as categorias empíricas. Cadernos de Sociologia, Porto Alegre, v. 6, p. 76-88, 1994. 
SCHNEIDER, Sergio. UFRGS, 2009. A pluriatividade na agricultura familiar. Porto Alegre: Ed. da UFRGS, 2003. 2009. A diversidade da agricultura familiar. 2. ed. Porto Alegre: Ed. da UFRGS,

; CASSOL, Abel. Diversidade e heterogeneidade da agricultura familiar no Brasil e algumas implicações para políticas públicas. In: DELGADO, Guilherme; BERGAMASCO, Sonia Maria Pessoa Pereira (Org.). Agricultura Familiar brasileira: desafios e perspectivas de futuro. Brasília: Ministério do Desenvolvimento Agrário, 2017.

SEYFERTH, Giralda. Campesinato e o Estado no Brasil. Mana, Rio de Janeiro, v. 17, n. 2, p. $395-417,2011$.

VEIGA, José Eli da. O desenvolvimento agrícola: uma visão histórica. São Paulo: EDUSP, 1991.

WANDERLEY, Maria de Nazareth Baudel. Raízes históricas do campesinato brasileiro. In: TEDESCO, João Carlos (Org.). Agricultura familiar: realidades e perspectivas. Passo Fundo: EdUPF, 1999. p. 23-56.

Agricultura familiar e campesinato: rupturas e continuidades. Estudos Sociedades e Agricultura, Rio de Janeiro, n. 21, p. 42-61, out. 2003.

O mundo rural como um espaço de vida: reflexões sobre a propriedade da terra, agricultura familiar e ruralidade. Porto Alegre: Ed. da UFRGS, 2015. 